University of Nebraska - Lincoln

DigitalCommons@University of Nebraska - Lincoln

\title{
A visible band index for remote sensing leaf chlorophyll content at the canopy scale
}

E. Raymond Hunt Jr.

USDA Agricultural Research Service, Raymond.Hunt@ars.usda.gov

Paul C. Doraiswamy

USDA Agricultural Research Service

James E. McMurtrey

USDA Agricultural Research Service

Craig S.T. Daughtry

USDA Agricultural Research Service

Eileen M. Perry

Future Farming Systems Research

See next page for additional authors

Follow this and additional works at: https://digitalcommons.unl.edu/usdaarsfacpub

Hunt, E. Raymond Jr.; Doraiswamy, Paul C.; McMurtrey, James E.; Daughtry, Craig S.T.; Perry, Eileen M.; and Akhmedov, Bakhyt, "A visible band index for remote sensing leaf chlorophyll content at the canopy scale" (2013). Publications from USDA-ARS / UNL Faculty. 1156.

https://digitalcommons.unl.edu/usdaarsfacpub/1156

This Article is brought to you for free and open access by the U.S. Department of Agriculture: Agricultural Research Service, Lincoln, Nebraska at DigitalCommons@University of Nebraska - Lincoln. It has been accepted for inclusion in Publications from USDA-ARS / UNL Faculty by an authorized administrator of DigitalCommons@University of Nebraska - Lincoln. 


\section{Authors}

E. Raymond Hunt Jr., Paul C. Doraiswamy, James E. McMurtrey, Craig S.T. Daughtry, Eileen M. Perry, and Bakhyt Akhmedov 


\title{
A visible band index for remote sensing leaf chlorophyll content at the canopy scale
}

\author{
E. Raymond Hunt Jr. ${ }^{\mathrm{a}, *}$, Paul C. Doraiswamy ${ }^{\mathrm{a}, 1}$, James E. McMurtrey ${ }^{\mathrm{a}, 2}$, Craig S.T. Daughtry ${ }^{\mathrm{a}}$, \\ Eileen M. Perry ${ }^{\mathrm{b}}$, Bakhyt Akhmedov ${ }^{\mathrm{a}}$
}

a USDA Agricultural Research Service, Hydrology and Remote Sensing Laboratory, Beltsville Agricultural Research Center, 10300 Baltimore Avenue, Beltsville, MD 20705, USA

${ }^{\mathrm{b}}$ Future Farming Systems Research, Department of Primary Industries, 110 Natimuk Road, Private Bag 260, Horsham, VIC 3401, Australia

\section{A R T I C L E I N F O}

\section{Article history:}

Received 17 July 2012

Accepted 27 July 2012

\section{Keywords:}

Spectral indices

Triangular greenness index (TGI)

Airborne Visible/Infrared Imaging

Spectrometer (AVIRIS)

PROSPECT

SAIL

Landsat Thematic Mapper (TM)

Nitrogen fertilization

Zea mays

\begin{abstract}
A B S T R A C T
Leaf chlorophyll content is an important variable for agricultural remote sensing because of its close relationship to leaf nitrogen content. The triangular greenness index (TGI) was developed based on the area of a triangle surrounding the spectral features of chlorophyll with points at $\left(670 \mathrm{~nm}, R_{670}\right)$, ( $550 \mathrm{~nm}, R_{550}$ ), and ( $480 \mathrm{~nm}, R_{480}$ ), where $R_{\lambda}$ is the spectral reflectance at wavelengths of 670,550 and 480 , respectively. The equation is TGI $=-0.5\left[(670-480)\left(R_{670}-R_{550}\right)-(670-550)\left(R_{670}-R_{480}\right)\right]$. In 1999 , investigators funded by NASA's Earth Observations Commercialization and Applications Program collaborated on a nitrogen fertilization experiment with irrigated maize in Nebraska. Airborne Visible/Infrared Imaging Spectrometer (AVIRIS) data and Landsat 5 Thematic Mapper (TM) data were acquired along with leaf chlorophyll meter and other data on three dates in July during late vegetative growth and early reproductive growth. TGI was consistently correlated with plot-averaged chlorophyll-meter values at the spectral resolutions of AVIRIS, Landsat TM, and digital cameras. Simulations using the Scattering by Arbitrarily Inclined Leaves (SAIL) canopy model indicate an interaction among TGI, leaf area index (LAI) and soil type at low crop LAI, whereas at high LAI and canopy closure, TGI was only affected by leaf chlorophyll content. Therefore, TGI may be the best spectral index to detect crop nitrogen requirements with low-cost digital cameras mounted on low-altitude airborne platforms.
\end{abstract}

(C) 2012 Published by Elsevier B.V.

\section{Introduction}

Agricultural crops have large nitrogen requirements, but the demand for fertilizer is variable because some nitrogen is supplied by soil biogeochemical processes (Scharf et al., 2002a; Meisinger et al., 2008). Uniform rates of fertilization for a single field may result in large areas having excess nitrogen, which is either leached into the ground water or lost in gaseous forms (e.g. nitrous oxide, a greenhouse gas). As a low-cost alternative to plant or soil sampling, remote sensing of either foliar nitrogen or chlorophyll content may supply information on the spatial variability of soil nitrogen supply (Schepers et al., 1996; Scharf et al., 2002a; Gitelson et al., 2005; Fox and Walthall, 2008; Hatfield et al., 2008; Meisinger et al., 2008).

There are different types of sensors that measure the amount of reflected solar radiation: from low-cost multispectral to high-cost imaging spectrometers, from low spatial to high spatial resolution,

\footnotetext{
* Corresponding author. Tel.: +1 301504 5278; fax: +1 301504 8931. USDA is an equal opportunity provider and employer.

E-mail address: Raymond.Hunt@ars.usda.gov (E.R. Hunt Jr.).

1 Deceased.

2 Retired.
}

and from ground-based to satellite. The forefront of imaging spectroscopy is the estimation of leaf chlorophyll content, leaf nitrogen content, leaf area index (LAI) and other variables by model inversion, including atmospheric and topographic corrections (Botha et al., 2007; Houborg et al., 2009; Jacquemoud et al., 2009; Kokaly et al., 2009; Vohland et al., 2010). Newer techniques for estimating leaf and canopy chlorophyll content use various methods to determine the geometric area bounded by a spectral reflectance curve (Oppelt and Mauser, 2004; Haboudane et al., 2008; Delegido et al., 2010). However, agricultural management generally requires information within very short windows of time (Moran et al., 1997; Pinter et al., 2003). Furthermore, it is uncertain that more detailed information from imaging spectrometers will lead to better decisions for crop nitrogen management, for example, compared to ground-based on-the-go sensors (Shanahan et al., 2008). Digital cameras and aerial photography are low-cost methods used for determining areas with nitrogen deficiency (Blackmer et al., 1996; Adamsen et al., 1999; Scharf et al., 2002a; Dani et al., 2005). However, these low-cost methods need better methods to extract the information desired by managers (Hunt et al., 2005).

Spectral indices are an important method for extracting information from remotely sensed data because indices reduce, but do not eliminate, effects of soils, topography, and view angle (Jackson 
Table 1

Various remote sensing indices related to vegetation cover and chlorophyll content.

\begin{tabular}{|c|c|c|c|c|}
\hline Name & Type $^{\mathrm{a}}$ & Abbrev. & Equation $^{\mathrm{b}}$ & References \\
\hline $\begin{array}{l}\text { Ratio vegetation index (also called } \\
\text { simple ratio) }\end{array}$ & Red-NIR & RVI & $R_{n} / R_{r}$ & $\begin{array}{l}\text { Jordan (1969) and Pearson } \\
\text { and Miller (1972) }\end{array}$ \\
\hline $\begin{array}{l}\text { Normalized difference vegetation } \\
\text { index }\end{array}$ & Red-NIR & NDVI & $\left(R_{n}-R_{r}\right) /\left(R_{n}+R_{r}\right)$ & $\begin{array}{l}\text { Rouse et al. (1974) and } \\
\text { Tucker (1979) }\end{array}$ \\
\hline Soil adjusted vegetation index & Red-NIR & SAVI & $(1+0.5)\left(R_{n}-R_{r}\right) /\left(R_{n}+R_{r}+0.5\right)$ & Huete (1988) \\
\hline $\begin{array}{l}\text { Modified soil adjusted vegetation } \\
\text { index }\end{array}$ & Red-NIR & MSAVI & $0.5\left\{2 \cdot R_{n}+1-\sqrt{ }\left[\left(2 \cdot R_{n}+1\right)^{2}-8\left(R_{n}-R_{r}\right)\right]\right\}$ & Qi et al. (1994) \\
\hline $\begin{array}{l}\text { Optimized soil adjusted vegetation } \\
\text { index }\end{array}$ & Red-NIR & OSAVI & $(1+0.16)\left(R_{n}-R_{r}\right) /\left(R_{n}+R_{r}+0.16\right)$ & Rondeaux et al. (1996) \\
\hline Enhanced vegetation index & Vis-NIR & EVI & $2.5\left(R_{n}-R_{r}\right) /\left(R_{n}+6 \cdot R_{r}-7.5 \cdot R_{b}+1\right)$ & Huete et al. (2002) \\
\hline Triangular vegetation index & Vis-NIR & TVI & $0.5\left[120\left(R_{n}-R_{g}\right)-200\left(R_{r}-R_{g}\right)\right]$ & Broge and Leblanc (2000) \\
\hline $\begin{array}{l}\text { Second modified triangular } \\
\text { vegetation index }\end{array}$ & Vis-NIR & MTVI2 & $\begin{array}{l}1.5\left[2.5\left(R_{n}-R_{g}\right)-2.5\left(R_{r}-R_{g}\right)\right] / \\
\sqrt{ }\left[\left(2 \cdot R_{n}+1\right)^{2}-6 \cdot R_{n}-5 \cdot \sqrt{ }\left(R_{r}\right)-0.5\right]\end{array}$ & Haboudane et al. (2004) \\
\hline Chlorophyll vegetation index & Vis-NIR & CVI & $R_{n} \cdot R_{r} / R_{g}^{2}$ & Vincini et al. (2008) \\
\hline $\begin{array}{l}\text { Green normalized difference } \\
\text { vegetation index }\end{array}$ & Green-NIR & gNDVI & $\left(R_{n}-R_{g}\right) /\left(R_{n}+R_{g}\right)$ & Gitelson et al. (1996) \\
\hline Chlorophyll index - green & Green-NIR & $\mathrm{CI}-\mathrm{G}$ & $R_{n} / R_{g}-1$ & Gitelson et al. (2003) \\
\hline $\begin{array}{l}\text { Normalized green red difference } \\
\text { index }\end{array}$ & Vis & NGRDI & $\left(R_{g}-R_{r}\right) /\left(R_{g}+R_{r}\right)$ & Tucker (1979) \\
\hline Green leaf index & Vis & GLI & $\left(2 \cdot R_{g}-R_{r}-R_{b}\right) /\left(2 \cdot R_{g}+R_{r}+R_{b}\right)$ & Louhaichi et al. (2001) \\
\hline $\begin{array}{l}\text { Visible atmospherically resistant } \\
\text { index }\end{array}$ & Vis & VARI & $\left(R_{g}-R_{r}\right) /\left(R_{g}+R_{r}-R_{b}\right)$ & Gitelson et al. (2002) \\
\hline $\begin{array}{l}\text { Normalized difference red edge } \\
\text { index }\end{array}$ & RE-NIR & NDREI & $\left(R_{n}-R_{r e}\right) /\left(R_{n}+R_{r e}\right)$ & Gitelson and Merzlyak (1994) \\
\hline Chlorophyll index - red edge & RE-NIR & CI-RE & $R_{n} / R_{r e}-1$ & Gitelson et al. (2003) \\
\hline MERIS total chlorophyll index & RE-NIR & MTCI & $\left(R_{750}-R_{710}\right) /\left(R_{710}-R_{680}\right)$ & Dash and Curran (2004) \\
\hline $\begin{array}{l}\text { Modified chlorophyll absorption } \\
\text { reflectance index }\end{array}$ & Red-RE & MCARI & {$\left[\left(R_{700}-R_{670}\right)-0.2\left(R_{700}-R_{550}\right)\right]\left(R_{700} / R_{670}\right)$} & Daughtry et al. (2000) \\
\hline $\begin{array}{l}\text { Transformed chlorophyll } \\
\text { absorption reflectance index }\end{array}$ & Red-RE & TCARI & $3\left[\left(R_{700}-R_{670}\right)-0.2\left(R_{700}-R_{550}\right)\left(R_{700} / R_{670}\right)\right]$ & Haboudane et al. (2002) \\
\hline Triangular chlorophyll index & Red-RE & $\mathrm{TCI}$ & $1.2\left(R_{700}-R_{550}\right)-1.5\left(R_{670}-R_{550}\right) \cdot \sqrt{ }\left(R_{700} / R_{670}\right)$ & Haboudane et al. (2008) \\
\hline Combined index with TCARI & Red-RE-NIR & & TCARI/OSAVI & Haboudane et al. (2004) \\
\hline Combined index with MCARI & Vis-RE-NIR & & MCARI/MTVI2 & Eitel et al. $(2007,2008)$ \\
\hline Triangular greenness index & Vis & TGI & $-0.5\left[\left(\lambda_{r}-\lambda_{b}\right)\left(R_{r}-R_{g}\right)-\left(\lambda_{r}-\lambda_{g}\right)\left(R_{r}-R_{b}\right)\right]$ & Hunt et al. (2011) \\
\hline
\end{tabular}

a Indices are grouped based on the major wavelengths used: NIR (n, 760-900 nm), red edge of chlorophyll absorption (re, 700-730 nm), red (r, 630-690 nm), green (g,

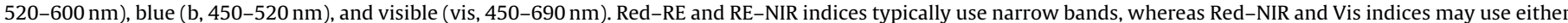
broad or narrow wavebands. Wavelength ranges for overlapping digital camera bands are: red 580-670 nm, green 480-610 nm, and blue 400-520 nm (Hunt et al., 2005).

${ }^{\mathrm{b}} R_{\lambda}$ is the reflectance at wavelength $\lambda ; R_{n}, R_{r e}, R_{r}, R_{g}$, and $R_{b}$ are the reflectances for NIR, RE, red, green, and blue bands, respectively.

and Huete, 1991; Hatfield et al., 2004, 2008; Hatfield and Prueger, 2010). Spectral indices are also an important method for analyzing imaging spectrometer data (Gitelson, 2012; Zhu et al., 2012). Visible and near-infrared spectral indices are sensitive to both chlorophyll content and LAI (Gitelson et al., 2002; Baret et al., 2007), so development of better indices with increased sensitivity to chlorophyll and decreased sensitivity to LAI may help fertilizer management for crops.

Most spectral indices today are calculated using ratios or normalized differences of two or three bands (Table 1), although originally, there was more diversity among spectral indices (Jackson and Huete, 1991). Broge and Leblanc (2000) developed the triangular vegetation index (TVI) based on the area of a triangle with vertices at green, red and NIR wavelengths (Table 1), which is sensitive to both chlorophyll content and LAI. In order to predict leaf nitrogen status, Haboudane et al. (2008) created the triangular chlorophyll index based on green, red and red-edge $(710-730 \mathrm{~nm})$ bands. Red-edge bands are deployed on many satellite sensors (Eitel et al., 2007; Herrmann et al., 2011; Ramoelo et al., 2012) and increase sensitivity to chlorophyll content (Gitelson et al., 2005; Gitelson, 2012). However, red-edge bands are generally not available on low-cost multispectral sensors, which have broad bands at visible wavelengths; therefore, a visible-band index called the triangular greenness index (TGI) was developed (Hunt et al., 2011).

In 1999, a group of investigators funded by the NASA Earth Observations Commercialization and Applications Program (EOCAP) pooled resources and conducted a nitrogen fertilization experiment with irrigated maize at Shelton, NE USA. Using Airborne Visible/Infrared Imaging Spectrometer (AVIRIS) data from the experiment, derivative indices were evaluated by Estep and Carter (2005) and other spectral indices were evaluated by Perry and Roberts (2008). We used datasets acquired during this experiment to test the response of TGI to leaf chlorophyll content and to compare the results with other vegetation and chlorophyll indices.

\section{Methods}

\subsection{Study site and experimental design}

On 29 April 1999, maize (Zea mays L) was planted in an irrigated 64-ha field $\left(40^{\circ} 45^{\prime} 39^{\prime \prime} \mathrm{N}, 98^{\circ} 43^{\prime} 35^{\prime \prime} \mathrm{W}\right)$ near Shelton, Nebraska, USA (Fig. 1). The east-west rows were spaced $0.76 \mathrm{~m}$ apart and the average plant density for the field was $8.3 \mathrm{~m}^{-2}$. The dominant soil types were a Hord silt loam (fine-silty, mixed, mesic, Pachic Haplustoll) and a Blendon loam (coarse-loamy, mixed, superactive, mesic, Pachic Haplustoll). At planting, $20 \mathrm{~kg} \mathrm{~N} \mathrm{ha}^{-1}$ (as liquid ammonium polyphosphate) was applied along each planted row at a soil depth of $5-10 \mathrm{~cm}$.

Twenty plots $(75 \mathrm{~m} \times 90 \mathrm{~m})$ with different levels of applied nitrogen fertilizer were established along the center of the field in a randomized complete block design with four replications (Fig. 2). On 5 June 1999, sidedress fertilizer of $0,50,100,150$ or $200 \mathrm{~kg} \mathrm{~N} \mathrm{ha}^{-1}$ (as anhydrous ammonia) was applied to one plot in each block. During the sidedress fertilization, a mistake was made in programming the variable rate applicator; two applicator passes in the odd numbered plots received the treatment from the evennumbered plot directly north (Fig. 2). Two plots were left bare on the east and west edges of the field to serve as calibration targets. 


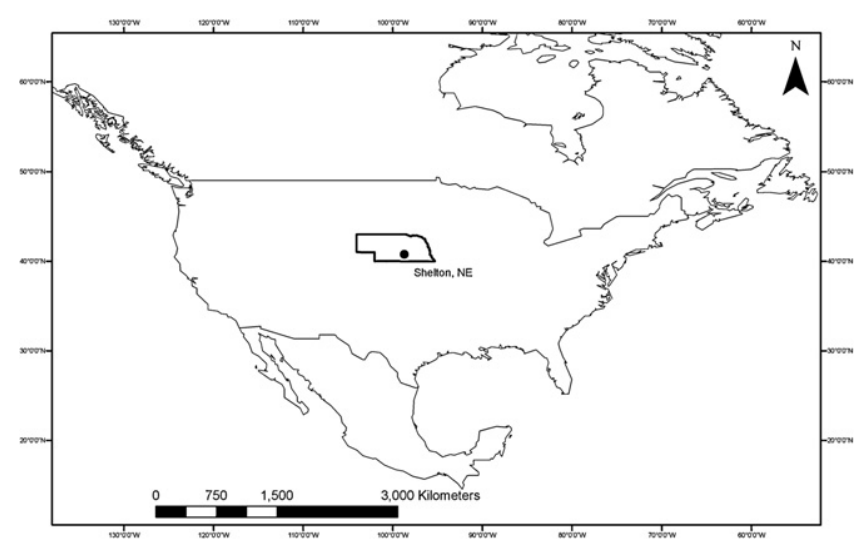

Fig. 1. Location of the field site near Shelton, Nebraska, USA.

To test detection accuracy, there were eight 100 -m long plots established with widths of $8 \mathrm{~m}, 16 \mathrm{~m}, 18 \mathrm{~m}$ or $24 \mathrm{~m}$, each with no sidedress fertilizer (Fig. 2). The remainder of the field was fertilized with $150 \mathrm{~kg} \mathrm{~N} \mathrm{ha}^{-1}$, which was the average amount of fertilizer applied to maize. Along the north edge of the plot, plots were established for which irrigation water was withheld, imposing water stress (Perry and Roberts, 2008).

Frequent measurements (about a week apart) were made in each plot starting 24 June 1999. LAI was measured at five locations per plot with an AccuPAR Ceptometer (Decagon Devices, Pullman, Washington, USA) using the procedure described by Wilhelm et al. (2000). The five locations were at the plot center, and at the center point of the north-east, north-west, south-west, and south-east plot quadrants around the plot center. Plant growth stage (Ritchie et al., 1993) was determined weekly in four rows per plot at 3 locations per row. Leaf chlorophyll meters (Minolta SPAD-502 meter, http://konicaminolta.com/products/instruments/spad/index.html) were used to monitor crop nitrogen status (Schepers et al., 1992; Varvel et al., 2007). Chlorophyll-meter values were obtained in four rows per plot, with 30 leaves per row, selected from the top-most fully expanded leaves with a visible leaf collar.

An ASD FieldSpec Pro FR spectrometer (Analytical Spectral Devices, Boulder, CO, USA) was mounted in an aerial lift about $18 \mathrm{~m}$ above the ground for canopy measurements during AVIRIS overflights on 6 July and 22 July. A $10^{\circ}$ fore-optic was used to restrict the

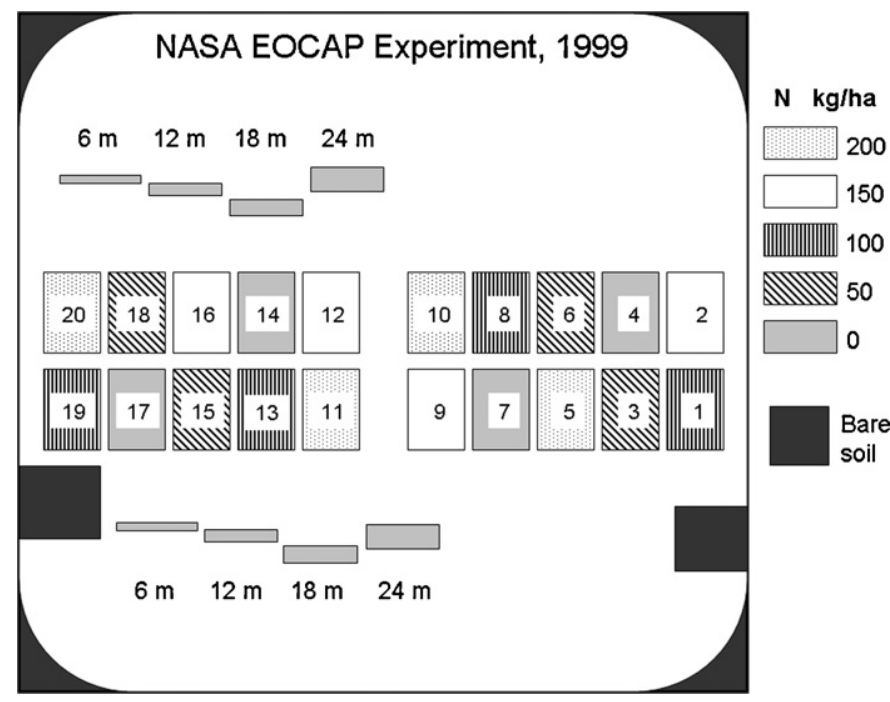

Fig. 2. Experimental layout for the nitrogen fertilization experiment in a 64-ha maize field that had center-pivot irrigation. North is to the top of the diagram. field of view to 3-m diameter. Measurements of a Spectralon panel (Labsphere Inc., North Sutton, New Hampshire, USA), also mounted on the aerial lift, were used to calculate spectral reflectance factors. All canopy measurements were made between 1000 and $1400 \mathrm{~h}$. The data were compared to plot averages of chlorophyll meter values.

On 22 July, four leaves were collected from three sample locations in each plot for spectral reflectance measurements. Reflectances were determined using an ASD FieldSpec Pro FR spectrometer attached to a LiCor (LiCor Inc., Lincoln, NE, USA) LI-1800-12 integrating sphere. One disk $\left(131 \mathrm{~mm}^{2}\right)$ per leaf was excised from each leaf, where the leaf was clamped onto the integrating sphere. The four leaf disks from each sample location were grouped together, leaf chlorophylls and carotenoids were extracted with dimethyl sulfoxide, and chlorophyll concentrations were determined using equations from Wellburn (1994). Because the chlorophyll content and chlorophyll meter values were not measured on the same leaves, the data could not be used to develop a calibration equation to estimate leaf chlorophyll content from the chlorophyll meter values. Leaf spectral and chlorophyll data were also acquired 17 June 1999 (12 days after sidedress fertilization); however, there were no differences among the plots.

\subsection{PROSPECT and SAIL model simulations}

Simulations of leaf spectral reflectance and transmittance were made for various leaf chlorophyll contents from 15 to $85 \mu \mathrm{g} \mathrm{cm}^{-2}$ using the PROSPECT Version 4 model (Jacquemoud et al., 1996, 2009; Feret et al., 2008). The leaf structure parameter was set at 1.5 , the water content was set at $0.015 \mathrm{~g} \mathrm{~cm}^{-2}$, and dry matter content was set at $0.005 \mathrm{~g} \mathrm{~cm}^{-2}$, which were about the median values for maize (E.R. Hunt, unpublished results).

The outputs from the PROSPECT model were used as inputs to the Scattering by Arbitrarily Inclined Leaves (SAIL) model (Verhoef, 1984). Various LAI were used from 0.01 to 7.0 and a spherical leaf angle distribution was assumed. Soil color affects canopy reflectance and vegetation indices, so the reflectance spectra of two soils were used in the SAIL model simulations. The first soil was a mixture of a Hord silt loam and a Blendon loam from Nebraska, USA. The second soil was a reddish Gaston (fine, mixed, active, thermic Humic Hapludult) from North Carolina, USA.

To determine if the Hord/Blendon and Gaston soils represented a reasonable range of reflectances, a soil spectral library of 785 soil profiles (4437 samples) was obtained from the World Agroforestry Center (ICRAF)-ISRIC World Soil Information (ICRAF-ISRIC, 2010). The soils are from 58 countries located in Africa, Asia, Europe, North America, and South America. The spectra were measured with an ASD FieldSpec FR (Shepherd and Walsh, 2002).

\subsection{Development of the triangular greenness index}

The triangular greenness index (TGI) estimates chlorophyll concentration in leaves and canopies based on the area of a triangle (Fig. 3) with three points: $\left(480 \mathrm{~nm}, R_{480}\right),\left(550 \mathrm{~nm}, R_{550}\right)$, and $\left(670 \mathrm{~nm}, R_{670}\right)$. Setting up a three by three matrix, the area of a triangle is calculated from matrix determinants. After factoring the terms:

$A= \pm 0.5\left[\left(\lambda_{1}-\lambda_{3}\right)\left(R_{1}-R_{2}\right)-\left(\lambda_{1}-\lambda_{2}\right)\left(R_{1}-R_{3}\right)\right]$

where $A$ is the triangular area, $\lambda_{1}-\lambda_{3}$ are wavelengths for the three points, and $R_{1}-R_{3}$ are reflectances for the three points, respectively. The order of bands is not important, but the order will affect whether the result is positive or negative (hence the \pm in Eq. (1)). Starting with red for convenience:

$\mathrm{TGI}=-0.5\left[190\left(R_{670}-R_{550}\right)-120\left(R_{670}-R_{480}\right)\right]$ 
where TGI has units of wavelength $\times$ reflectance, so using $\mu \mathrm{m}$ wavelength units or percent reflectance does not affect the value of TGI, after units are converted. Multispectral sensor bands or digital camera bands of red, green and blue may be used instead of narrow bands at 670,550 and $480 \mathrm{~nm}$, respectively. Then, $\lambda_{1}-\lambda_{3}$ are the centers of the wavebands and $R_{1}-R_{3}$ are the waveband reflectances.

\subsection{Remote sensing data and image analysis}

AVIRIS data were acquired at high altitude (20-m pixel) on 6 July 1999 and at low altitude (3-m pixel) on 22 July 1999. High altitude data were also acquired on 25 June 1999; however, visual inspection of the images showed there was considerable haze on that date. The AVIRIS data facility from the Jet Propulsion Laboratory (Pasadena, CA, USA) provided calibrated radiances. A Landsat 5 Thematic Mapper (TM) image (path 30, row 32) acquired on 16 July 1999 was obtained from the U.S. Geological Survey, EROS Data Center (Sioux Falls, SD, USA).

The AVIRIS and TM images were atmospherically corrected to land-surface reflectance using Atmospheric Correction Now (ACORN) version 5.5 (ImSpec LLC, http://www.imspec.com). Because the study area was small, the images were not geometrically registered. Instead, each plot center was linearly interpolated from the edges of the field as seen on the image. The areas in the odd-numbered plots with the $\mathrm{N}$-application errors were avoided in the high-altitude and low-altitude AVIRIS data. Data were analyzed using the Environment for Visualizing Images (ENVI version 4.7, ITT Visible Information Solutions, Boulder, CO, USA).

\section{Results}

\subsection{Soil analyses and model simulations}

In the PROSPECT leaf model simulations, TGI, increased as the total chlorophyll content decreased from 85 to $15 \mu \mathrm{g} \mathrm{cm}^{-2}$ (only the results for chlorophyll contents 45 and $15 \mu \mathrm{g} \mathrm{cm}^{-2}$ are shown Fig. 3). Both chlorophylls and carotenoids strongly absorb at $480 \mathrm{~nm}$, so there is little change in reflectance at blue wavelengths with a reduction in chlorophyll content. Chlorophyll $a$ has a much higher absorption coefficient at $670 \mathrm{~nm}$ compared to $550 \mathrm{~nm}$, so for

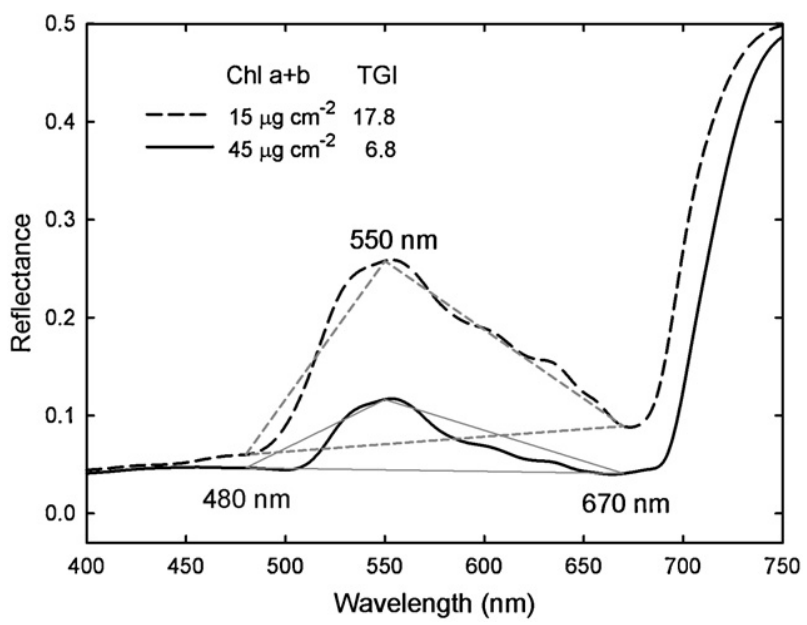

Fig. 3. PROSPECT model simulations of leaf spectral reflectance at chlorophyll $a+b$ contents of $15 \mu \mathrm{g} \mathrm{cm}^{-2}$ (nitrogen deficient) and $45 \mu \mathrm{g} \mathrm{cm}^{-2}$ (nitrogen sufficient). The triangular greenness index (TGI) is calculated from the area of a triangle defined by three points: $\left(480 \mathrm{~nm}, R_{480}\right),\left(550 \mathrm{~nm}, R_{550}\right)$, and $(670 \mathrm{~nm}$, $R_{670}$ ), where $R_{\lambda}$ is the reflectance at wavelength $\lambda$. The final equation is $\mathrm{TGI}=-0.5\left[190\left(R_{670}-R_{550}\right)-120\left(R_{670}-R_{480}\right)\right]$. Multispectral sensors use the center wavelength and reflectances for the blue, green and red bands.

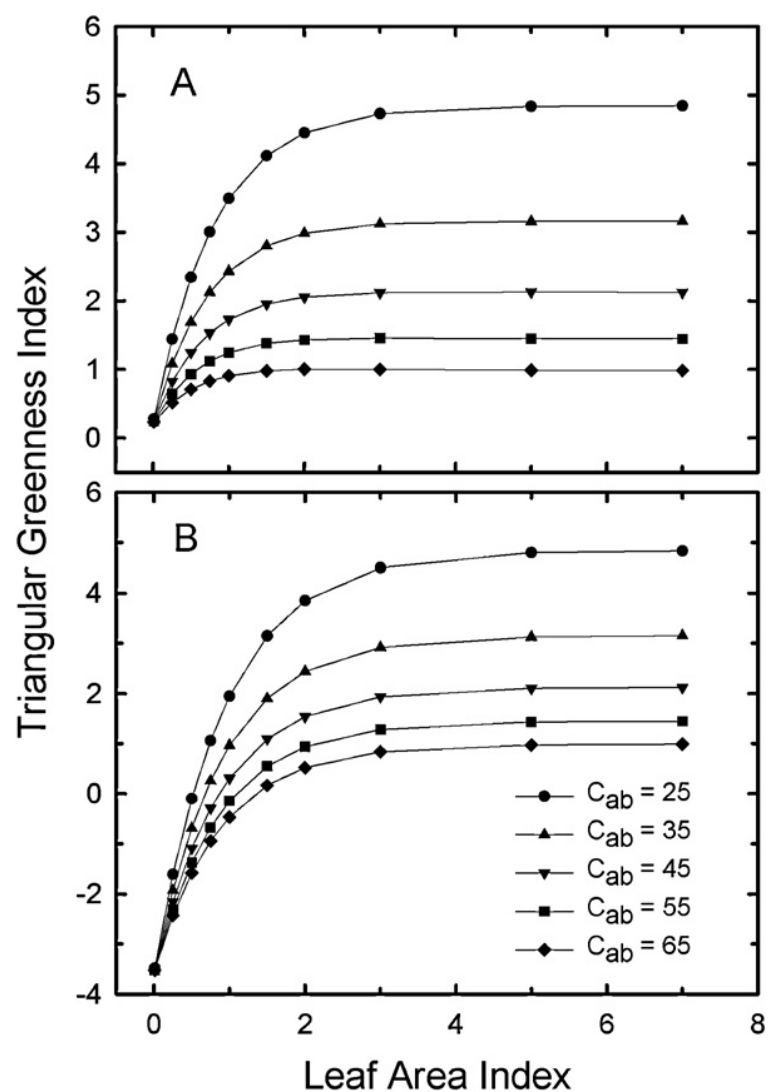

Fig. 4. SAIL model simulations showing the response of TGI to leaf area index (LAI) at various total leaf chlorophyll $\left(C_{a b}\right)$ contents. Two backgrounds were used for the simulations: (A) the Hord-Blendon soil found at the study site, and (B) a reddish Gaston soil.

a decrease in chlorophyll content, the increase at $550 \mathrm{~nm}$ is larger than the increase at $670 \mathrm{~nm}$ (Fig. 3).

The mean TGI from the ICRAF-ISRIC soil spectral library was -0.14 with a standard deviation of 2.05 using narrow bands (data not shown). Fifty percent of the samples (2203 out of 4437) had TGI between -1.0 and 1.0. The Hord and Blendon soils had a TGI of 0.27 , whereas the reddish Gaston soil had a negative TGI of -3.5 (Fig. 4). For both soil types, TGI increased rapidly at low values of LAI up to an LAI of about 1.5-2 (Fig. 4). The LAI-saturated value of canopy TGI at greater values of LAI was determined only by leaf chlorophyll content.

Band width affects the value of canopy TGI (Fig. 5). There were large decreases in TGI for a given leaf chlorophyll content from the narrow AVIRIS bands, moderate decreases for Landsat Thematic Mapper bands, and small decreases for the broad, overlapping bands of a commercial digital camera (Fig. 5). This was expected because averaging the green reflectance at $550 \mathrm{~nm}$ over a larger wavelength range reduces the green band reflectance. Furthermore, averaging the red reflectance at $670 \mathrm{~nm}$ over a larger wavelength range increases the red band reflectance.

A sensitivity analysis was conducted to determine optimal wavelengths for calculation of TGI. When narrow, 10-nm bands were shifted $\pm 20 \mathrm{~nm}$, one at a time, there were order of magnitude changes in TGI. There were also very large changes in TGI when all three bands were shifted $\pm 20 \mathrm{~nm}$ in the same direction. So for narrow bands, wavelengths at 670,550 and $480 \mathrm{~nm}$ were better for calculation of TGI. With broad bands, from either Landsat TM or digital cameras, shifts of the center wavelength $\pm 20 \mathrm{~nm}$ had very little effect on TGI. So for comparison of TGI among sensors, the red, green and blue wavelengths were kept constant at 670, 550 and $480 \mathrm{~nm}$, respectively. 


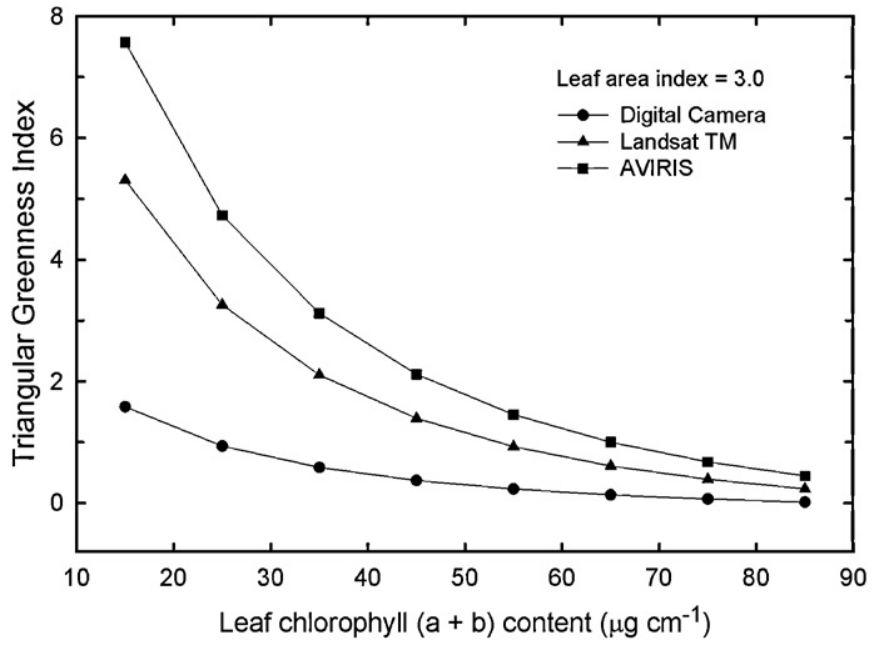

Fig. 5. SAIL model simulations showing the response of TGI to leaf chlorophyll content for three different sensors: (A) a commercial digital camera, (B) Landsat Thematic Mapper (TM), and (C) the Airborne Visible/Infrared Imaging Spectrometer (AVIRIS). LAI was 3.0 and the background was the Hord-Blendon soil found at the study site.

\subsection{Field and remote sensing data}

The experimental maize field was primarily in vegetative growth on 8 July, tasselling growth stage on 14 July, and silking stage on 22 July (Fig. 6A). The high-nitrogen plots initially
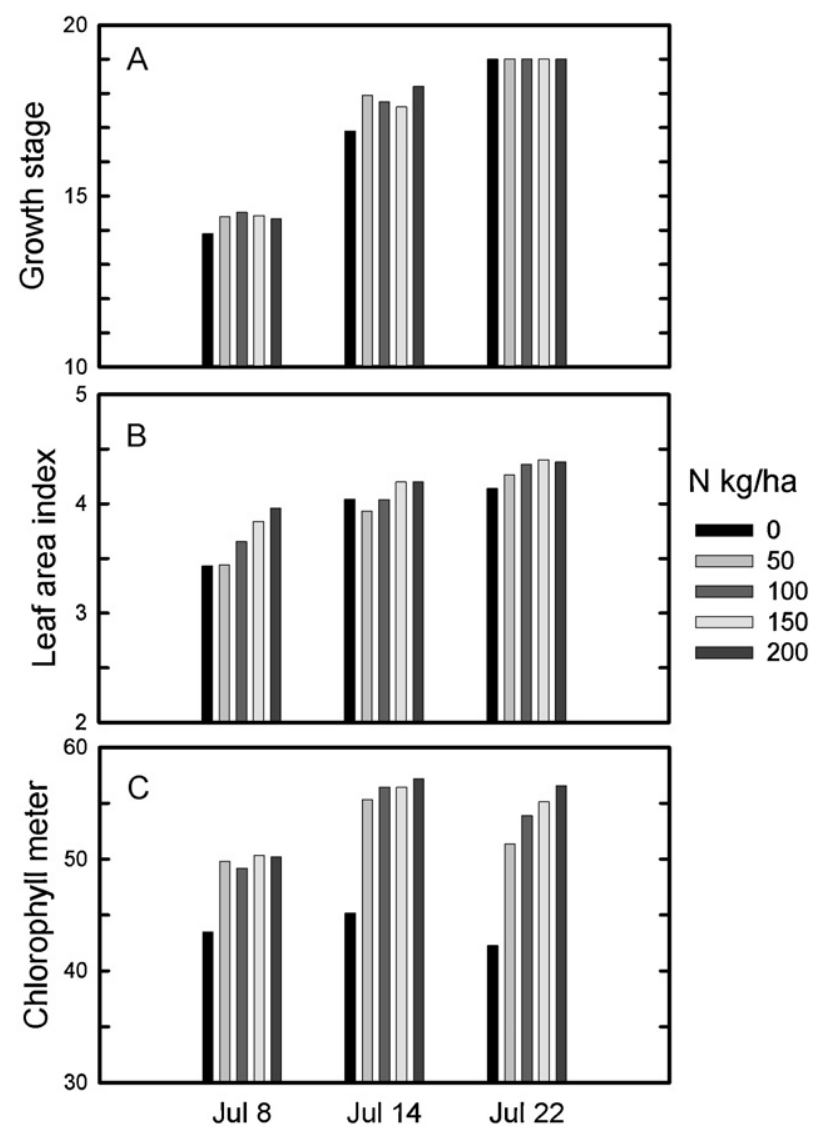

Fig. 6. Field data summary for three dates: (A) growth stage, (B) leaf area index, and (C) leaf chlorophyll meter values. Corn growth stage (Ritchie et al., 1993) is defined by the number of mature leaves with visible leaf collars during vegetative growth (for this variety, 17 leaves), then tasseling (stage 18), and finally reproductive stage 1 (silking, stage 19). grew faster than the low nitrogen plots, but by 22 July, there were only small differences in LAI among the treatments (Fig. 6B). Except for the low-nitrogen plots $\left(0 \mathrm{~kg} \mathrm{ha}^{-1} \mathrm{~N}\right)$, there were only small differences in chlorophyll meter values on 8 and 14 July (Fig. 6C). However, on 22 July, there were large differences in chlorophyll meter values among the $50-200 \mathrm{~kg} \mathrm{ha}^{-1} \mathrm{~N}$ treatments, in part because leaf nitrogen started to be re-allocated for grain production.

After a histogram stretch, the $0 \mathrm{~kg} \mathrm{ha}^{-1} \mathrm{~N}$ plots were detected in the high-altitude AVIRIS data acquired on 6 July, both in the true color (Fig. 7A) and the TGI images (Fig. 7B). The 12-m, 18-m and 24- $\mathrm{m}$ wide detection plots were detectable in the images, but the 6 - $\mathrm{m}$ wide plots were not (Fig. 7A and B). Furthermore, plots 3 and 13 ( $50 \mathrm{~kg} \mathrm{ha}^{-1} \mathrm{~N}$, Fig. 1 ) were also detected, which was probably facilitated by the two applicator passes with $0 \mathrm{~kg} \mathrm{ha}^{-1} \mathrm{~N}$. The other plots were not visually distinguishable, which was consistent with the chlorophyll meter data (Fig. 6C).

Only the $0 \mathrm{~kg} \mathrm{ha}^{-1} \mathrm{~N}$ plots were visible in the Landsat TM true color image after a histogram stretch (Fig. 7C), and were not detectable in the TGI image (Fig. 7D), except with prior knowledge of the applied $\mathrm{N}$ treatments. Only the $0 \mathrm{~kg} \mathrm{ha}^{-1} \mathrm{~N}$ plots had much lower chlorophyll meter values on 16 July, so this result was consistent with the field data. None of the narrow detection plots were distinguishable in either Fig. 7C or D.

The 22 July low-altitude AVIRIS data showed very clear differences in both the true color image (Fig. 7E) and the TGI image (Fig. 7F). However, as the leaf chlorophyll-meter data suggest, the largest differences were between the $0 \mathrm{~kg} \mathrm{ha}^{-1} \mathrm{~N}$ plots and the other plots. It was not surprising that all eight of the $0 \mathrm{~kg} \mathrm{ha}^{-1} \mathrm{~N}$ detection plots were visible, because the width of the narrowest plot was about two pixels wide for the low-altitude (3-m) AVIRIS data.

The field spectrometer data acquired from an aerial lift were not significantly different from the AVIRIS data acquired on either 6 July (Fig. 8A) or 22 July (Fig. 8B). However, the regression lines were significantly different between the two dates. For both dates, the linear relationship between TGI and chlorophyll-meter data was largely determined from the $0 \mathrm{~kg} \mathrm{ha}^{-1} \mathrm{~N}$ plots. Therefore, correlations between any index and chlorophyll-meter data depended on how well that index separates the $0 \mathrm{~kg} \mathrm{ha}^{-1} \mathrm{~N}$ plots from the other treatments.

\subsection{Comparison of TGI with other spectral indices}

The correlation coefficient between plot average leaf chlorophyll content and the plot-average chlorophyll-meter data was 0.85 on 22 July 1999 . From the leaf spectrometer and integrating sphere data, only two spectral indices were not correlated to leaf chlorophyll content and only four indices were not correlated to chlorophyll-meter data (Table 2). In general, indices based on a near-infrared band, such as the ratio vegetation index (RVI) or the normalized difference vegetation index (NDVI) were not as highly correlated with either chlorophyll-meter or totalchlorophyll data compared to visible-band only indices [TGI, visible atmospherically resistant index (VARI), normalized greenred difference index (NGRDI), and green leaf index (GLI)]. Indices using a red-edge band such as the normalized difference rededge index (NDREI) were about equal to visible-band indices (Table 2). Whereas all of the visible band indices were about equal using narrow bands, the correlation coefficients were lower for VARI, NGRDI, and GLI when the data were averaged to simulate digital camera bands (Table 2). The correlation coefficients with TGI remained about the same when spectral resolution was degraded.

For the high-altitude AVIRIS data acquired 6 July 1999, indices based on green/near-infrared combinations, indices based on 


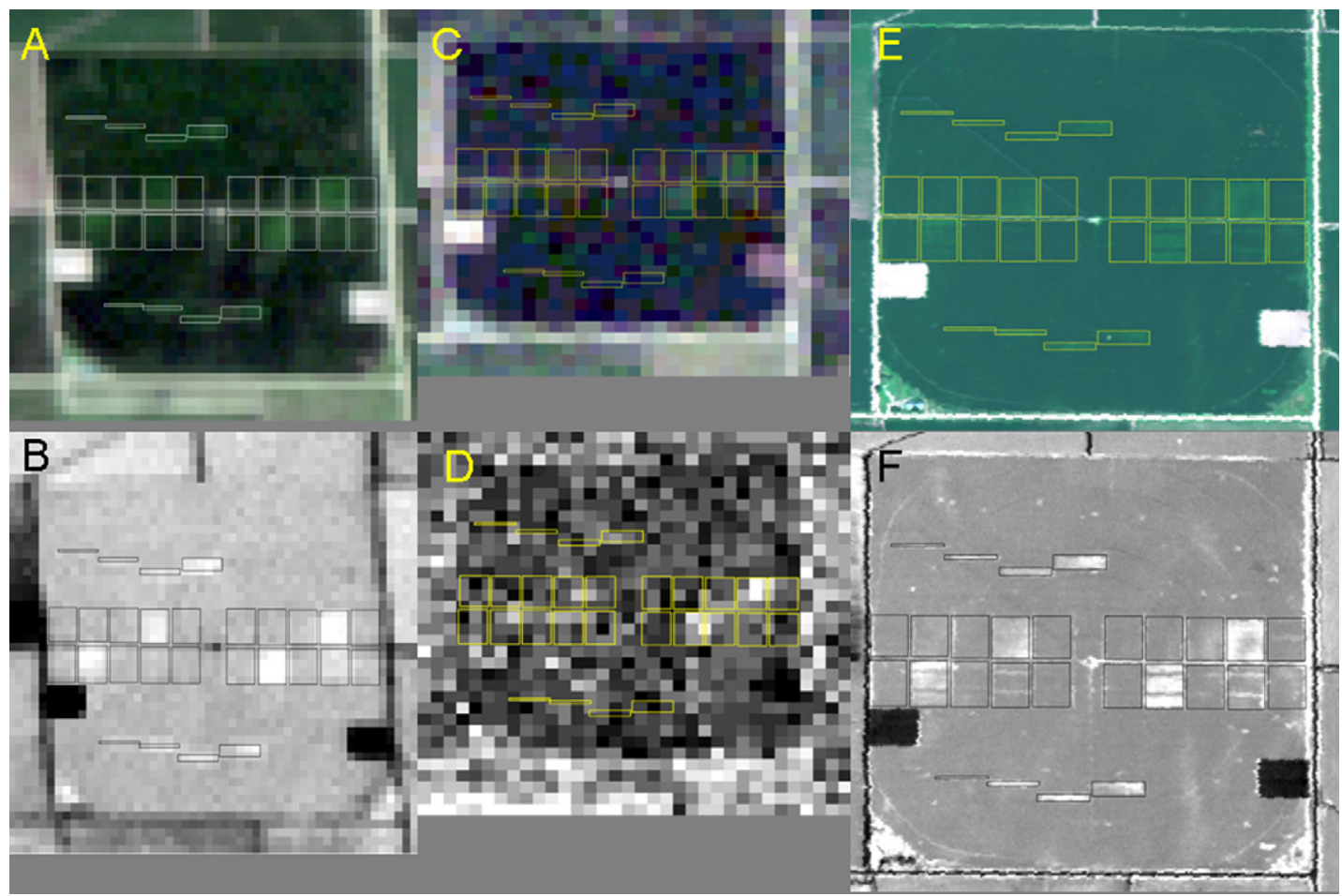

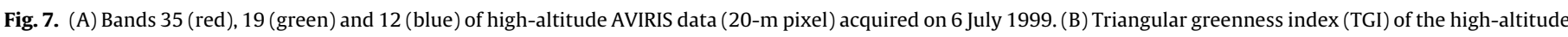

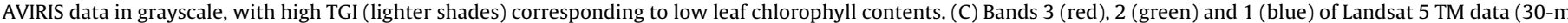

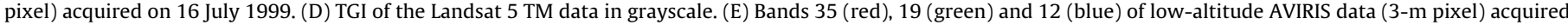
on 22 July 1999. (F) TGI of the low-altitude AVIRIS data in grayscale.

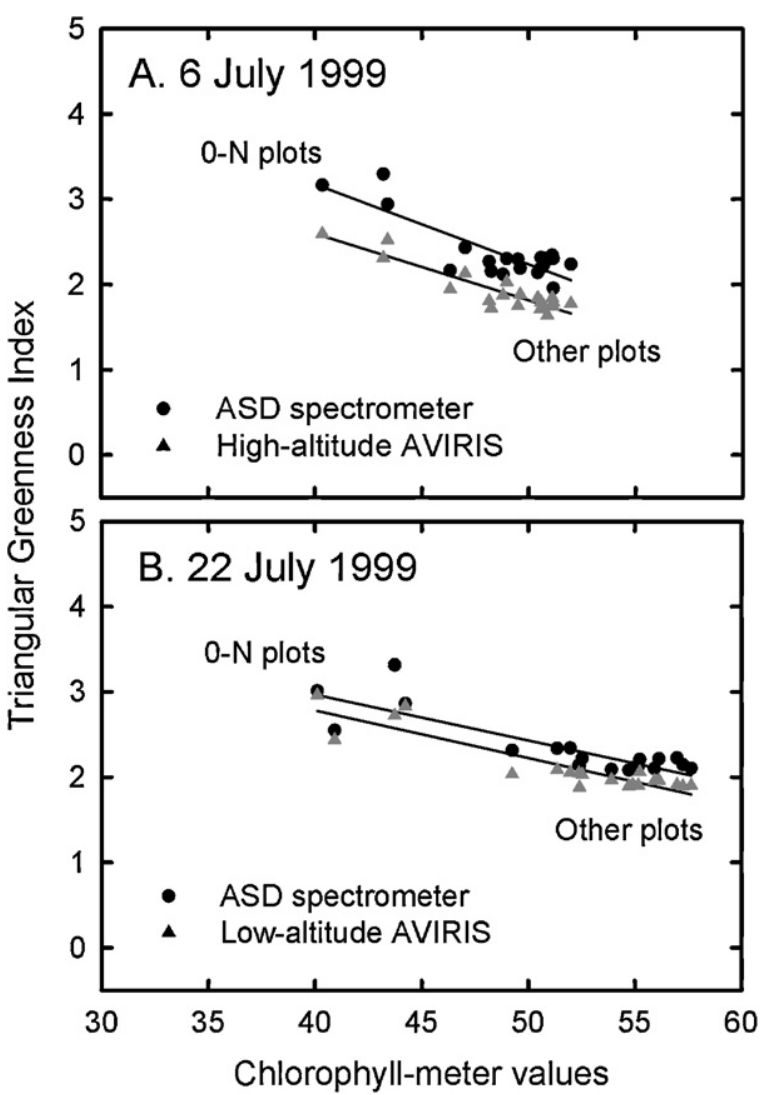

Fig. 8. TGI obtained from reflectance spectra obtained using an ASD spectrometer from an aerial lift and AVIRIS imagery for two dates: (A) 6 July 1999 and (B) 22 July 1999. The linear regressions are not significantly different between the ASD spectrometer and AVIRIS data for 6 July $(P=0.35)$ and 22 July $(P=0.20)$. There were significant differences between the two dates for both the ASD spectrometer $(P=0.018)$ and AVIRIS $(P=0.050)$ data. red-edge/near-infrared combinations and TGI performed better than red/near-infrared indices (Table 3). Two of the visible-band indices (VARI and NGRDI) had correlations that reversed from negative to positive. On 6 July, there were differences LAI among the treatments (Fig. 6B), so the positive correlations most likely caused by differences in leaf area index. Hunt et al. (2005) found that NGRDI was positively correlated with biomass (and thus LAI) in other experiments. For the Landsat TM data (Table 4), TGI had the best correlation with chlorophyll-meter data, followed closely by green/near-infrared indices such as the green normalized difference vegetation index (gNDVI) and the chlorophyll index - green (CI-G).

Similar to the leaf spectrometer data acquired on 22 July, almost every index was highly correlated with the chlorophyll-meter data for the low-altitude AVIRIS overflight on 22 July (Table 5). Exploration of the data showed that some novel band combinations and derivative indices had even higher correlation coefficients. For example, the first spectral derivative at $570 \mathrm{~nm}$ wavelength had a correlation coefficient of -0.95 (P.C. Doraiswamy, P.M. Zara, and J.M. McMurtrey, personal communication). However, these novel indices were not correlated with chlorophyll-meter data on the 6 July AVIRIS high-altitude overflight, and were not highly significant using either the leaf spectrometer data or SAIL model simulations.

\section{Discussion}

There were three results that indicated TGI has potential for nitrogen fertilizer management. The first was the correlations between TGI and chlorophyll meter/chlorophyll data were consistently among the best spectral indices for the three dates of image data, leaf spectrometer data, and SAIL model simulations. The second is that TGI was not sensitive to changes in LAI above 2.0, so TGI is a robust indicator of leaf chlorophyll content. This indicates that canopy closure, and not LAI per se, was the important canopy 
Table 2

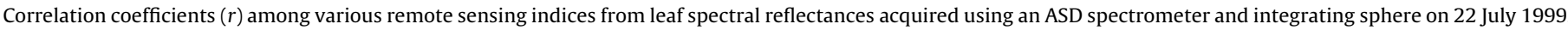

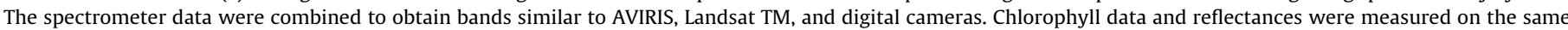

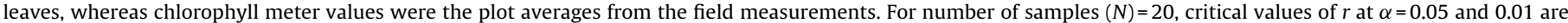
0.433 and 0.549 , respectively.

\begin{tabular}{|c|c|c|c|c|c|c|}
\hline \multirow[t]{2}{*}{ Index } & AVIRIS bands & TM bands & Digital camera bands & AVIRIS bands & TM bands & Digital camera bands \\
\hline & \multicolumn{3}{|c|}{ Total leaf chlorophyll $\left(\mu \mathrm{g} \mathrm{cm}^{-2}\right)$} & \multicolumn{3}{|c|}{ Plot chlorophyll meter values } \\
\hline RVI & 0.41 & 0.51 & $--^{a}$ & 0.52 & 0.61 & - \\
\hline NDVI & 0.37 & 0.50 & - & 0.45 & 0.51 & - \\
\hline SAVI & 0.53 & 0.56 & - & 0.40 & 0.62 & - \\
\hline MSAVI & 0.52 & 0.56 & - & 0.39 & 0.62 & - \\
\hline OSAVI & 0.55 & 0.56 & - & 0.63 & 0.73 & - \\
\hline EVI & 0.55 & 0.69 & - & 0.41 & 0.74 & - \\
\hline TVI & 0.46 & 0.49 & - & 0.51 & 0.54 & - \\
\hline MTVI2 & 0.29 & 0.43 & - & 0.39 & 0.49 & - \\
\hline CVI & 0.88 & 0.86 & - & 0.88 & 0.87 & - \\
\hline gNDVI & 0.78 & 0.76 & - & 0.80 & 0.79 & - \\
\hline CI-G & 0.80 & 0.77 & - & 0.83 & 0.81 & - \\
\hline NGRDI & -0.88 & -0.88 & -0.79 & -0.83 & -0.81 & -0.68 \\
\hline GLI & -0.89 & -0.89 & -0.80 & -0.83 & -0.83 & -0.78 \\
\hline VARI & -0.86 & -0.86 & -0.78 & -0.79 & -0.79 & -0.68 \\
\hline NDREI & 0.85 & - & - & 0.85 & - & - \\
\hline CI-RE & 0.83 & - & - & 0.86 & - & - \\
\hline MTCI & 0.86 & - & - & 0.89 & - & - \\
\hline MCARI & -0.87 & - & - & -0.85 & - & - \\
\hline TCARI & -0.86 & - & - & -0.85 & - & - \\
\hline $\mathrm{TCI}$ & -0.87 & - & - & -0.85 & - & - \\
\hline TCARI/OSAVI & -0.85 & - & - & -0.84 & - & - \\
\hline MCARI/MTVI2 & -0.84 & - & - & -0.83 & - & - \\
\hline TGI & -0.86 & -0.86 & -0.88 & -0.84 & -0.84 & -0.85 \\
\hline
\end{tabular}

a Not applicable.

variable. The third was the correlations did not depend on the spectral resolution of the sensor, as long as the TGI was not saturated at high values of leaf chlorophyll content. Spectral indices using a band at the red edge of the chlorophyll $a$ absorption spectrum were also consistently among the best spectral indices for estimating leaf chlorophyll content, as found in other studies (Yao et al., 2010). With the new commercial satellite systems, red-edge bands are available for estimating chlorophyll content (Eitel et al., 2007; Herrmann et al., 2011; Ramoelo et al., 2012). However, broad-band

Table 3

Correlation coefficients $(r)$ between various remote sensing indices and leaf chlorophyll meter data for high-altitude AVIRIS data acquired on 6 July 1999 . Chlorophyll meter values were acquired on 8 July 1999. The AVIRIS data were combined to be similar to the bands of TM and a digital camera. For $N=20$, critical values of $r$ at $\alpha=0.05$ and 0.01 are 0.433 and 0.549 , respectively.

\begin{tabular}{lccc}
\hline Index & AVIRIS bands & TM bands & Digital camera bands \\
\hline RVI & 0.63 & 0.71 & $-^{\mathrm{a}}$ \\
NDVI & 0.61 & 0.71 & - \\
SAVI & 0.40 & 0.43 & - \\
MSAVI & 0.41 & 0.43 & - \\
OSAVI & 0.47 & 0.53 & - \\
EVI & 0.38 & 0.42 & - \\
TVI & 0.27 & 0.31 & - \\
MTVI2 & 0.37 & 0.46 & - \\
CVI & 0.81 & 0.78 & - \\
gNDVI & 0.78 & 0.79 & - \\
CI-G & 0.77 & 0.78 & - \\
NGRDI & -0.35 & -0.093 & 0.47 \\
GLI & -0.70 & -0.71 & -0.60 \\
VARI & 0.031 & 0.38 & 0.70 \\
NDREI & 0.81 & - & - \\
CI-RE & 0.79 & - & - \\
MTCI & 0.87 & - & - \\
MCARI & -0.89 & - & - \\
TCARI & -0.91 & - & - \\
TCI & -0.83 & - & - \\
TCARI/OSAVI & -0.92 & - & - \\
MCARI/MTVI2 & -0.91 & - & - \\
TGI & -0.91 & -0.93 & -0.89 \\
\hline
\end{tabular}

a Not applicable. red-green-blue data are widely available and low-cost sensors may not have a red-edge band.

The results were very different between TGI and the normalized green-red difference index (NGRDI). The basic equation for calculating the area of a triangle is 0.5 base $\times$ height, and the difference between green and red determines the height of the triangle. Since the base of the triangle is fixed by the wavelength range, correlations of NGRDI with chlorophyll meter data were expected to be about equal to TGI. However, NGRDI was more sensitive to changes

Table 4

Correlation coefficients $(r)$ between various remote sensing indices and leaf chlorophyll meter data for Landsat 5 TM data acquired on 16 July 1999. Leaf chlorophyll meter data were acquired on 13 July 1999. For $N=20$, critical values of $r$ at $\alpha=0.05$ and 0.01 are 0.433 and 0.549 , respectively.

\begin{tabular}{lc}
\hline Index & TM bands \\
\hline RVI & 0.27 \\
NDVI & 0.28 \\
SAVI & 0.41 \\
MSAVI & 0.41 \\
OSAVI & 0.39 \\
EVI & 0.44 \\
TVI & 0.14 \\
MTVI2 & 0.18 \\
CVI & 0.69 \\
gNDVI & 0.75 \\
CI-G & 0.74 \\
NGRDI & -0.52 \\
GLI & -0.49 \\
VARI & -0.51 \\
NDREI & $-{ }^{\mathrm{a}}$ \\
CI-RE & - \\
MTCI & - \\
MCARI & - \\
TCARI & - \\
TCI & - \\
TCARI/OSAVI & - \\
MCARI/MTVI2 & - \\
TGI & -0.78 \\
\hline
\end{tabular}

\footnotetext{
a Not applicable.
} 
Table 5

Correlation coefficients $(r)$ between vegetation and chlorophyll indices and leaf chlorophyll meter data for low-altitude AVIRIS data acquired on 22 July 1999. The AVIRIS data were combined to be similar to the bands of TM and a digital camera. ASD spectrometer data acquired from an aerial lift has similar correlations. For $N=20$, critical values of $r$ at $\alpha=0.05$ and 0.01 are 0.433 and 0.549 , respectively.

\begin{tabular}{|c|c|c|c|}
\hline Index & AVIRIS & TM bands & Camera bands \\
\hline RVI & 0.82 & 0.82 & $-\mathrm{a}$ \\
\hline NDVI & 0.82 & 0.82 & - \\
\hline SAVI & 0.74 & 0.64 & - \\
\hline MSAVI & 0.76 & 0.66 & - \\
\hline OSAVI & 0.79 & 0.73 & - \\
\hline EVI & 0.73 & 0.61 & - \\
\hline TVI & 0.64 & 0.50 & - \\
\hline MTVI2 & 0.72 & 0.64 & - \\
\hline CVI & 0.92 & 0.91 & - \\
\hline gNDVI & 0.89 & 0.88 & - \\
\hline CI-G & 0.90 & 0.89 & - \\
\hline NGRDI & -0.92 & -0.89 & -0.87 \\
\hline GLI & -0.91 & -0.90 & -0.89 \\
\hline VARI & -0.91 & -0.91 & -0.84 \\
\hline NDREI & 0.76 & - & - \\
\hline CI-RE & 0.76 & - & - \\
\hline MTCI & 0.89 & - & - \\
\hline MCARI & -0.89 & - & - \\
\hline TCARI & -0.88 & - & - \\
\hline $\mathrm{TCI}$ & -0.89 & - & - \\
\hline TCARI/OSAVI & -0.89 & - & - \\
\hline MCARI/MTVI2 & -0.89 & - & - \\
\hline TGI & -0.91 & -0.91 & -0.92 \\
\hline
\end{tabular}

a Not applicable.

in LAI as indicated by comparing the correlations between the highaltitude and low-altitude AVIRIS data (Tables 3 and 5). Furthermore, the sensitivity of NGRDI to LAI was found in other studies (Hunt et al., 2005).

The limitation on TGI, other spectral indices, and chlorophyll meters for nitrogen management is the requirement that chlorophyll content is correlated to fertilizer requirements. Correlations found for the 6 July AVIRIS image and 16 July Landsat 5 TM image were mostly caused by the data from the plots with $0 \mathrm{~kg} \mathrm{Nha}^{-1}$. Scharf et al. (2002b) found that nitrogen fertilizer applications could be delayed during maize vegetative growth (growth stages V1-V15), but losses in yield occurred when maize reaches reproductive growth stages without sufficient nitrogen. The AVIRIS data acquired on 6 July indicated that it is possible to use remote sensing to detect severe nitrogen deficiency $\left(0 \mathrm{~kg} \mathrm{~N} \mathrm{ha}^{-1}\right.$ plots $)$. However, in this region $150 \mathrm{~kg} \mathrm{~N} \mathrm{ha}^{-1}$ is the typical rate of application, therefore areas of intermediate $\mathrm{N}$ (plots with 50 and $100 \mathrm{~kg} \mathrm{Nha}^{-1}$ ) would have been missed during the 6 July overflight.

The requirement of TGI for high LAI or canopy closure may be eliminated with the use of very-high-spatial-resolution sensors ( $<10-\mathrm{mm}$ pixels), such as digital cameras, because only pixels that are pure vegetation need to be analyzed (Scharf and Lory, 2002). The degradation of spectral resolution by using broad bands is compensated by the higher spatial resolution. Sensor radiometric resolution is also important, and 8-bit imagery may not be sufficient; the radiometric resolution of many digital cameras is greater with cameras' native raw image format (Verhoeven, 2010). However, a potential problem with using digital cameras to calculate TGI is that the digital numbers are based on camera exposure, and not spectral reflectance or radiance; hence more research is needed on radiometric calibration of digital cameras.

Digital cameras may be operated from light aircraft or small unmanned aircraft systems (Hunt et al., 2005; Lelong et al., 2008; Sakamoto et al., 2011; Lebourgeois et al., 2012), which can be rapidly deployed to acquire data during brief windows of good weather. Since the area of acquisition is at the field or farm level, the data can be processed quickly to provide recommendations for nitrogen application rates. Furthermore, the same digital images can be examined for other agricultural problems such as insect damage, plant disease, and high weed density. Often, plant diseases and other elemental deficiencies reduce leaf chlorophyll content (Knipling, 1970; Masoni et al., 1996), so high TGI may be a symptom of problems other than low leaf nitrogen content. However acquiring data at very-high spatial resolution will present other problems for image analyses, such as image registration, because the pixel size is much less than the accuracy available from most global positioning systems. A potential solution to these problems is to analyze each image as a separate plot for monitoring.

\section{Conclusions}

The triangular greenness index (TGI) was developed to be sensitive to leaf chlorophyll content at the canopy scale and to be relatively insensitive to LAI. The data acquired during 1999 for irrigated maize during NASA EOCAP experiment showed that TGI was among the best spectral indices, including those that use rededge bands. Nitrogen must be applied during vegetative growth to prevent yield losses, which was 6 July in this experiment, but only the plots with severe nitrogen deficiency (very low chlorophyll contents) were detectable. If remote sensing is to be used for nitrogen management, intermediate levels of chlorophyll content must be detected reliably. Therefore, TGI may be the spectral index by which digital cameras mounted on low-flying airborne platforms may be used for a low-cost assessment of crop fertilizer requirements.

\section{Acknowledgements}

We thank the original group of investigators, the support from the NASA Earth Observations Commercialization and Applications Program (EOCAP) to these investigators, and the many people who planned and conducted this experiment. We are especially grateful to Dr. James Schepers, USDA-ARS (retired), Lincoln, NE, who led the field measurements team.

\section{Appendix A. Supplementary data}

Supplementary data associated with this article can be found, in the online version, at http://dx.doi.org/10.1016/j.jag.2012.07.020.

\section{References}

Adamsen, F.J., Pinter, P.J., Barnes, E.M., LaMorte, R.L., Wall, G.W., Leavitt, S.W., Kimball, B.A., 1999. Measuring wheat senescence with a digital camera. Crop Science 39, 719-724.

Baret, F., Houlès, V., Guérif, M., 2007. Quantification of plant stress using remote sensing observations and crop models: the case of nitrogen management. Journal of Experimental Botany 58, 869-880.

Blackmer, T.M., Schepers, J.S., Varvel, G.E., Meyer, G.E., 1996. Analysis of aerial photography for nitrogen stress within corn fields. Agronomy Journal 88, 729-733.

Botha, E.J., Leblon, B., Zebarth, Z., Watmough, E., 2007. Non-destructive estimation of potato leaf chlorophyll from canopy hyperspectral reflectance using the inverted PROSAIL model. International Journal of Applied Earth Observation and Geoinformation 9, 360-374

Broge, N.H., Leblanc, E., 2000. Comparing predictive power and stability of broadband and hyperspectral vegetation indices for estimation of green leaf area index and canopy chlorophyll density. Remote Sensing of Environment 76, 156-172.

Dani, D.N., Bannur, S.V., Kulgod, S.V., Sainis, J.K., 2005. Estimation of chlorophyl in leaves using portable digital camera. Physiological and Molecular Biology of Plants 11, 321-326.

Daughtry, C.S.T, Walthall, C.L., Kim, M.S., Brown de Colstoun, E., McMurtrey, J.E. 2000. Estimating corn leaf chlorophyll concentration for leaf and canopy reflectance. Remote Sensing of Environment 74, 229-239.

Dash, J., Curran, P.J., 2004. The MERIS terrestrial chlorophyll index. International Journal of Remote Sensing 25, 5403-5413.

Delegido, J., Alonso, L., González, G., Moreno, J., 2010. Estimating chlorophyll content of crops from hyperspectral data using a normalized area over reflectance curve (NAOC). International Journal of Applied Earth Observation and Geoinformation 12, 165-174. 
Eitel, J.U.H., Long, D.S., Gessler, P.E., Hunt, E.R., 2008. Combined spectral index to improve ground-based estimates of nitrogen status in dryland wheat. Agronomy Journal 100, 1694-1702.

Eitel, J.U.H., Long, D.S., Gessler, P.E., Smith, A.M.S., 2007. Using in situ measurements to evaluate the new RapidEye ${ }^{\mathrm{TM}}$ satellite series for prediction of wheat nitrogen status. International Journal of Remote Sensing 28, 4183-4190.

Estep, L., Carter, G.A., 2005. Derivative analysis of AVIRIS data for crop stress detection. Photogrammetric Engineering and Remote Sensing 71, 1417-1421.

Feret, J.B., François, C., Asner, G.P., Gitelson, A.A., Martin, R.E., Bidel, L.P.R., Ustin, S.L., le Maire, G., Jaquemoud, S., 2008. PROSPECT-4 and 5: advances in the leaf optical properties model separating photosynthetic pigments. Remote Sensing of Environment 112, 3030-3043.

Fox, R.H., Walthall, C.L., 2008. Crop monitoring technologies to assess nitrogen status. In: Schepers, J.S., Raun, W.R. (Eds.), Nitrogen in Agricultural Systems. Agronomy Monograph, 49. ASA-CSSA-SSSAJ, Madison, WI, pp. 647-674.

Gitelson, A.A., 2012. Nondestructive estimation of foliar pigment (chlorophylls, carotenoids and anthocyanins) contents: evaluating a semianalytical threeband model. In: Thenkabail, P.S., Lyon, J.G., Huete, A. (Eds.), Hyperspectral Remote Sensing of Vegetation. CRC Press, Boca Raton, FL, pp. 141-165.

Gitelson, A.A., Gritz, Y., Merzlyak, M.N., 2003. Relationships between leaf chlorophyll content and spectral reflectance algorithms for non-destructive chlorophyl assessment in higher plants. Journal of Plant Physiology 160, 271-282.

Gitelson, A.A., Kaufman, Y.J., Merzlyak, M.N., 1996. Use of a green channel in remote sensing of global vegetation from EOS-MODIS. Remote Sensing of Environment 58, 289-298.

Gitelson, A.A., Kaufman, Y.J., Stark, R., Rundquist, D., 2002. Novel algorithms for remote estimation of vegetation fraction. Remote Sensing of Environment 80 $76-87$.

Gitelson, A.A., Merzlyak, M.N., 1994. Quantitative estimation of chlorophyll using reflectance spectra. Journal of Photochemistry and Photobiology B 22, 247-252.

Gitelson, A.A., Viña, A., Ciganda, V., Rundquist, D.C., Arkebauer, T.J., 2005. Remote estimation of canopy chlorophyll content in crops. Geophysical Research Letters 32, L08403.

Haboudane, D., Miller, J.R., Tremblay, N., Zarco-Tejada, P.J., Dextraze, L., 2002 Integrated narrow-band vegetation indices for prediction of crop chlorophyl content for application to precision agriculture. Remote Sensing of Environment $81,416-426$

Haboudane, D., Miller, J.R., Pattey, E., Zarco-Tejada, P.J., Strachan, I.B., 2004. Hyperspectral vegetation indices and novel algorithms for predicting green LAI of crop canopies: modeling and validation in the context of precision agriculture. Remote Sensing of Environment 90, 337-352.

Haboudane, D., Tremblay, N., Miller, J.R., Vigneault, P., 2008. Remote estimation of crop chlorophyll content using spectral indices derived from hyperspectral data. IEEE Transactions of Geoscience and Remote Sensing 46, 423-437.

Hatfield, J.L., Gitelson, A.A., Schepers, J.S., Walthall, C.L., 2008. Application of spectral remote sensing for agronomic decisions. Agronomy Journal 100, S117-S131.

Hatfield, J.L., Prueger, J.H., 2010. Value of using different vegetation indices to quantify agricultural crop characteristics at different growth stages under varying management practices. Remote Sensing 2, 562-578.

Hatfield, J.L., Prueger, J.H., Kustas, W.P., 2004. Remote sensing of dryland crops. In: Ustin, S.L. (Ed.), Remote Sensing for Natural Resource Management and Environmental Monitoring. , 3rd ed. John Wiley \& Sons, Hoboken, NJ, pp. 532-568.

Herrmann, I Pimstein, A. Karnieli, A Cohen, Y Alchanatis, V., Bonfil, D. 2011. LA assessment of wheat and potato crops by VEN $\mu$ S and Sentinel-2 bands. Remote Sensing of Environment 115, 2141-2151

Houborg, R., Anderson, M.C., Daughtry, C.S.T., 2009. Utility of an image-based canopy reflectance modeling tool for remote estimation of LAI and leaf chlorophyl content at the field scale. Remote Sensing of Environment 113, 259-274.

Huete, A.R., 1988. A soil-adjusted vegetation index (SAVI). Remote Sensing of Environment 25, 295-309.

Huete, A., Didan, K., Miura, T., Rodriguez, E.P., Gao, X., Ferreira, L.G., 2002. Overview of the radiometric and biophysical performance of the MODIS vegetation indices. Remote Sensing of Environment 83, 195-213.

Hunt, E.R., Cavigelli, M., Daughtry, C.S.T., McMurtrey, J.E., Walthall, C.L., 2005. Evaluation of digital photography from model aircraft for remote sensing of crop biomass and nitrogen status. Precision Agriculture 6, 359-378.

Hunt, E.R., Daughtry, C.S.T., Eitel, J.U.H., Long, D.S., 2011. Remote sensing leaf chlorophyll content using a visible band index. Agronomy Journal 103, 1090-1099.

ICRAF-ISRIC, 2010. A Globally Distributed Soil Spectral Library: Visible Near Infrared Diffuse Reflectance Spectra. World Agroforestry Centre (ICRAF) and ISRIC - World Soil Information, Nairobi, Kenya, http://africasoils.net/data/ICRAFISRICspectra (accessed 23.11.10).

Jackson, R.D., Huete, A.R., 1991. Interpreting vegetation indices. Preventive Veterinary Medicine 11, 185-200.

Jacquemoud, S., Ustin, S.L., Verdebout, J., Schmuck, G., Andreoli, G., Hosgood, B., 1996. Estimating leaf biochemistry using the PROSPECT leaf optical properties mode. Remote Sensing of Environment 56, 194-202.

Jacquemoud, S., Verhoef, W., Baret, F., Bacour, C., Zarco-Tejada, P.J., Asner, G.P. François, C., Ustin, S.L., 2009. PROSPECT + SAIL models: a review of use for vegetation characterization. Remote Sensing of Environment 113 (Suppl.), S56-S66.

Jordan, C.F., 1969. Derivation of leaf area index from quality of light on the forest floor. Ecology 50, 663-666.

Knipling, E.B., 1970. Physical and physiological basis for the reflectance of visible and near-infrared radiation from vegetation. Remote Sensing of Environment 1 , 155-159.
Kokaly, R.F., Asner, G.P., Ollinger, S.V., Martin, M.E., Wessman, C.A., 2009. Characterizing canopy biochemistry from imaging spectroscopy and its application to ecosystem studies. Remote Sensing of Environment 113 (Suppl.), S78-S91.

Lebourgeois, V., Bégué, A., Labbé, S., Houlès, M., Martiné, J.F., 2012. A light-weigh multi-spectral aerial imaging system for nitrogen crop monitoring. Precision Agriculture 13, 525-541.

Lelong C.C.D., Burger, P., Jubelin, G., Roux, B., Labbé, S., Baret, F, 2008. Assessment of unmanned aerial vehicles imagery for quantitative monitoring of wheat crop in small plots. Sensors 8, 3557-3585.

Louhaichi, M., Borman, M.M., Johnson, D.E., 2001. Spatially located platform and aerial photography for documentation of grazing impacts on wheat. Geocarto International $16,65-70$

Masoni, A., Ercoli, L., Mariotti, M., 1996. Spectral properties of leaves deficient in iron, sulfur, magnesium, and manganese. Agronomy Journal 88, 937-943.

Meisinger, J.J., Schepers, J.S., Raun, W.R., 2008. Crop nitrogen requirement and fertilization. In: Schepers, J.S., Raun, W.R. (Eds.), Nitrogen in Agricultural Systems. Agronomy Monograph, 49. ASA-CSSA-SSSAJ, Madison, WI, pp. 563-612.

Moran, M.S., Inoue, Y., Barnes, E.M., 1997. Opportunities and limitations for imagebased remote sensing in precision crop management. Remote Sensing of Environment 61, 319-346.

Oppelt, N., Mauser, W., 2004. Hyperspectral monitoring of physiological parameters of wheat during a vegetation period using AVIS data. International Journal of Remote Sensing 25, 145-157.

Pearson, R.L., Miller, L.D.,1972. Remote mapping of standing crop biomass for estimation of the productivity of the shortgrass prairie. In: Proceedings of the Eighth International Symposium on Remote Sensing of Environment. Environmental Research Institute of Michigan, Ann Arbor, MI, pp. 1357-1381.

Perry, E.M., Roberts, D.A., 2008. Sensitivity of narrow-band and broad-band indices for assessing nitrogen availability and water stress in an annual crop. Agronomy Journal 100, 1211-1219.

Pinter, P.J., Hatfield, J.L., Schepers, J.S., Barnes, E.M., Moran, M.S., Daughtry, C.S.T. Upchurch, D.R., 2003. Remote sensing for crop management. Photogrammetric Engineering and Remote Sensing 69, 647-664.

Qi, J., Chehbouni, A., Huete, A.R., Kerr, Y.H., Sorooshian, S., 1994. A modified soi adjusted vegetation index. Remote Sensing Environment 48, 119-126.

Ramoelo, A., Skidmore, A.K., Cho, M.A., Schlerf, M., Mathieu, R., Heitkönig, I.M.A. 2012. Regional estimation of savanna grass nitrogen using the red-edge band of the spaceborne RapidEye sensor. International Journal of Applied Earth Observation and Geoinformation 19, 151-162.

Ritchie, S.W., Hanway, J.J., Benson, G.O., 1993. How a Corn Plant Develops (Specia Report 48). Iowa State University, Ames, IA.

Rondeaux, G., Steven, M., Baret, F., 1996. Optimization of soil-adjusted vegetation indices. Remote Sensing of Environment 55, 95-107.

Rouse, J.W., Haas, R.H., Schell, J.A., Deering, D.W., 1974. Monitoring vegetation systems in the Great Plains with ERTS. In: Freden, S.C., Mercanti, E.P., Becker, M (Eds.), Third Earth Resources Technology Satellite-1 Symposium, Vol. 1: Technical Presentations, NASA SP-351. National Aeronautics and Space Administration, Washington, DC, pp. 309-317.

Sakamoto, T., Shibayama, M., Kimura, A., Takada, E., 2011. Assessment of digita camera-derived vegetation indices in quantitative monitoring of season rice growth. ISPRS Journal of Photogrammetry and Remote Sensing 66, 872-882.

Scharf, P.C., Lory, J.A., 2002. Calibrating corn color from aerial photographs to predict sidedress nitrogen need. Agronomy Journal 94, 397-404.

Scharf, P.C., Schmidt, J.P., Kitchen, N.R., Sudduth, K.A., Hong, S.Y., Lory, J.A., Davis, J.G., 2002a. Remote sensing for nitrogen management. Journal of Soil and Water Conservation 57, 518-524.

Scharf, P.C., Wiebold, W.J., Lory, J.A., 2002b. Corn yield response to nitrogen fertilize timing and deficiency level. Agronomy Journal 94, 435-441.

Schepers, J.S., Blackmer, T.M., Wilhelm, W.W., Resende, M., 1996. Transmittance and reflectance measurements of corn leaves from plants with different nitrogen and water supply. Journal of Plant Physiology 148, 523-529.

Schepers, J.S., Francis, D.D., Vigil, M., Bigelow, F.E., 1992. Comparison of corn leaf nitrogen concentration and chlorophyll meter readings. Communications in Soil Science and Plant Analysis 23, 2173-2187.

Shanahan, J.F., Kitchen, N.R., Raun, W.R., Schepers, J.S., 2008. Responsive in-season nitrogen management for cereals. Computers and Electronics in Agriculture 61 $51-62$.

Shepherd, K.D., Walsh, M.G., 2002. Development of reflectance spectral libraries for characterization of soil properties. Soil Science Society of America Journal 66 988-998.

Tucker, C.J., 1979. Red and photographic infrared linear combinations for monitoring vegetation. Remote Sensing of Environment 8, 127-150.

Varvel, G.E., Wilhelm, W.W., Shanahan, J.F., Schepers, J.S., 2007. An algorithm for corn nitrogen recommendations using a chlorophyll meter based sufficiency index. Agronomy Journal 99, 701-706.

Verhoef, W., 1984. Light scattering by leaf layers with application to canopy reflectance modeling: the SAIL model. Remote Sensing of Environment 16, $125-141$

Verhoeven, G.J.J., 2010. It's all about the format - unleashing the power of RAW aerial photography. International Journal of Remote Sensing 31 2009-2042.

Vincini, M., Frazzi, E., D’Alessio, P., 2008. A broad-band leaf chlorophyll index at the canopy scale. Precision Agriculture 9, 303-319.

Vohland, M., Mader, S., Dorigo, W., 2010. Applying different inversion techniques to retrieve stand variables of summer barley with PROSPECT + SAIL. 
International Journal of Applied Earth Observation and Geoinformation 12, 71-80.

Wellburn, A.R., 1994. The spectral determination of chlorophylls $a$ and $b$, as well as total carotenoids, using various solvents with spectrometers of different resolution. Journal of Plant Physiology 144, 307-313.

Wilhelm, W.W., Ruwe, K., Schlemmer, M.R., 2000. Comparisons of three leaf area index meters in a corn canopy. Crop Science 40, 1179-1183.
Yao, X., Zhu, Y., Tian, Y.C., Feng, W., Cao, W.X., 2010. Exploring hyperspectral bands and estimation indices for leaf nitrogen accumulation in wheat. Journal of Applied Earth Observation and Geoinformation 12, 89-100.

Zhu, Y., Wang, W., Yao, X., 2012. Estimating leaf nitrogen concentration (LNC) of cereal crops with hyperspectral data. In: Thenkabail, P.S., Lyon, J.G., Huete, A. (Eds.), Hyperspectral Remote Sensing of Vegetation. CRC Press, Boca Raton, FL, pp. 187-206. 